\title{
De maras a marabuntas. El miedo como dispositivo gubernamental, una lectura desde El Salvador
}

\author{
Ana Bengoa Valdés ${ }^{1}$ \\ Universidad Nacional Autónoma de México, Ciudad de México, México. \\ Email: abenval@gmail.com
}

\begin{abstract}
Resumen: Muchos de los jóvenes migrantes salvadoreños que se refugiaron de la guerra civil y la miseria en los suburbios de Los Ángeles, en la década de los ochenta, encontraron otras formas de cobijo y cuidado, desvinculadas de cualquier arraigo nacional: las maras. A fines de la década de los noventa, las enormes cantidades de deportados provenientes del proceso de criminalización y estigmatización de otredades extranjeras que habitaban los guetos de Estados Unidos, fueron reemplazados en los guetos centroamericanos y en sus extensiones penitenciarias. Hoy las políticas punitivas y sus brazos mediáticos definen a las maras como "organizaciones transnacionales de pandillas criminales”. Intentaremos en este artículo hacer una lectura crítica de la violencia que cimienta ese marco interpretativo; un intento de desmontaje de lo que invisibiliza esa forma de mirada que sólo ve lo sugerido al temor y la opinión, participando de la reproducción de lo que supone condena: la violencia.
\end{abstract}

Palabras clave: Maras, violencia estructural, miedo, racismo de Estado, campos de concentración.

\section{From maras to marabuntas. Fear as governmental dispositive, a reading from El Salvador}

\begin{abstract}
Many young Salvadoran migrants who fled civil war and misery in the suburbs of Los Angeles, in the eighties, found other forms of shelter and care, unrelated to any national roots: the Maras. In the late nineties, the huge amounts of deportees from the process of criminalization and stigmatization of foreign otherness that inhabited the ghettos of North America were re stationed in the Central American ghettos and their prisions extensions. Today punitive policies and its media arm define Maras as "transnational criminal organization gangs.” This article will try to make a critical reading of the violence that is at the base of that interpretive framework; an attempt to dismantle that which that gaze makes invisible for it only sees what is suggested to fear and the opinion, participating in the reproduction of what it supposedly condemns: violence.
\end{abstract}

Keywords: Maras, structural violence, fear, state racism, concentration camps. 


\title{
De maras para marabuntas. Medo como um dispositivo governamental, uma leitura a partir de El Salvador
}

Resumo: Muitos dos jovens migrantes salvadorenhos que fugiram da guerra civil e a miséria nos subúrbios de Los Angeles, na década de oitenta, encontrou outras formas de abrigo e cuidados, desvinculados de qualquer raiz nacional: as maras. No final dos anos noventa, a enorme quantidade de deportados gerados pelo processo de criminalização e estigmatização de alteridades estrangeiras que habitavam os guetos dos Estados Unidos, foram realocadosnos guetos centro-americanos e nas suas extensões prisionais. Hoje as políticas punitivas e seus braçosmidiáticos definem às maras como “organizações transnacionais de gangues criminosas”. Este artigo irá tentar fazer uma leitura crítica da violência que cimenta essa estrutura interpretativa; numa tentativa de desmantelar aquilo que torna invisível essa forma de olhar que apenas enxerga o sugerido pelo temor e a opinião, participando da reprodução do que se supõe condena: a violência.

Palavras-chave: Maras, violência estrutural, medo, racismo de Estado, campos de concentração.

\author{
$* * *$ \\ Porque a fin de cuentas esta capa de lo real, \\ es aquella donde se elabora la partición \\ entre lo que se admite como real y el resto.
}

Tiqqun.

\section{Introducción}

Tras las enormes cantidades de migraciones salvadoreñas que se refugiaron de la guerra civil y la miseria en los suburbios de Los Ángeles, California, en la década de los ochenta; tras el desprecio, discriminación y maltrato recibido en aquel refugio, nacieron otras formas de cobijo y cuidado, desvinculadas de cualquier arraigo nacional. Desde las calles, dejaron de ser simples parias, para pasar a ser lo que desde los aparatos gubernamentales y medios de comunicación (producción/difusión masiva de enunciados) conocemos hoy como maras: "organizaciones transnacionales de pandillas criminales”. Intentaremos en este artículo hacer una lectura crítica de la violencia que cimienta ese marco interpretativo; un intento de desmontaje de lo que invisibiliza esa forma de mirada que sólo ve lo sugerido al temor y la opinión, participando de la amnesia y la reproducción de lo que supone condena: la violencia.

El efecto del horror se expresa de maneras diferenciales: exposición diferencial a la violencia y a la muerte. La violencia no es propiedad exclusiva de ciertos actos ni actores, sino que se distribuye entre los actos y sus contextos, entre actividad e inactividad, entre tiempo y espacio.Desde ahí, anatemizar la violencia, condenarla como “mala”, parece ser una operación 
ideológica por excelencia, una mistificación que colabora con la invisibilización de las formas fundamentales de la violencia estructural (•i•ek, 2010: 244). A su vez, como dice Judith Butler,el afecto, en tanto pasión y padecimiento, "nunca es solamente nuestro: desde el principio, el afecto nos viene comunicado desde otra parte. Nos dispone para percibir el mundo de cierta manera, para dejar entrar ciertas dimensiones del mundo y oponer resistencia a otras” (Butler, 2010: 79).

La escenificación de la violencia, su ubicación y localización en determinados cuerpos estigmatizados, portadores de aquello que será incluido en el marco que ciñe lo visto e interpretado como violencia, a su vez, obscurece el lugar en que el marco se sitúa. Esto es, el tiempo y el espacio que le es cualidad constitutiva al cuerpo avistado. La mara que, desde el lenguaje popular salvadoreño o argot significa simplemente "grupo de amigos”, ha devenido marabunta: “enjambre de hormigas migrantes, carnívoras, que arrasan con todo a su paso”. Estos cuerpos demonizados, considerados carentes de cultura o portadores de culturas anómalas, de monstruos culturales, sonlos hijos del desplazamiento forzado,de la violencia estructural, de la guerra civil y la miseria, hijos de guetos de Los Ángeles, de la deportación y el retorno a una patria que finalmente les da un lugar permanente que habitar: la cárcel.

El tema de este artículo, sin embargo, no es la vulnerabilidad, mucho menos la victimización, sino la violencia objetiva, sistemática y sistémica, oculta tras las operaciones de visibilización exacerbada que ubican hoy a las maras o pandillas como centro mercadotécnico de las agendas de gobiernoen El Salvador (sin importar si su procedencia sea de derecha o izquierda), haciendo uso de ello para la reproducción de un sistema político-económico históricamente sustentado en las armas, y presentando a la relación Estado-Capital como mediación existencialmente neutra, con el subterfugio de preservar con la violencia institucional a un supuesto tejido social queconsta de antecedentes concretos de su depredación gubernamental.

Para esto, comenzaremos haciendo un breve recorrido de la violencia estructural, histórica y no por ello pasada de El Salvador: la impronta de su tradición armada y la función de esta forma de violencia en las relaciones entre política y economía. En este sentido, haremos una revisión de los procesos de militarización anteriores a la guerra civil, el intento de desmilitarización del Estado y las fuerzas políticas inscrito en los Acuerdos de Paz de Chapultepec en 1992, y los procesos de remilitarización iniciados en la década de los noventay acentuados radicalmente en el siglo XXI: todo esto desde una lectura que no disocie la relación entre violencia, economía y política. En el segundo apartado, nos enfocaremos en los decretos con fuerza de ley que ponen en vigencia la producción y reproducción de estas formas de violencia: leyes para la criminalización de la pertenencia a estos grupos que operan más allá de cualquier hecho calificado como delito, haciendo de la pertenencia el hecho que es delito y gestando, con esto, una particular forma de racismo de Estadoen sentido hiperbólico (más que deri- 
vado del concepto de raza, de cultura o, más específicamente de "contra cultura”) que mantiene hoy saturadas las cárceles de El Salvador, instaurando una violencia institucional cuya función no pasa por la corrección del cuerpo individual sino por la (re) producción de un cuerpo colectivo clasificado y devenido peligroso. Veremos en los últimos apartados a qué reflexiones nos lleva este análisis.

\section{La tradición armada: economía, política y violencia}

Slavoj •i•ek en sus ensayos Sobre la violencia hace algunas reflexiones sobre la violencia que él denomina “objetiva”, constituida por la violencia simbólica y la que sistemáticamente se ejerce desde la política y la economía formal, distinguiéndola de lo que denomina violencia "subjetiva" en tanto capacidad perceptiva de lo que será definido como tal. Jugando con estas categorías, el autor plantea que la violencia objetiva sería lo que sostiene el nivel cero, la plataforma normalizada, frente a lo que “subjetivamente” percibimos como violento. De ahí dirá que debemos tener precaución con la fascinación de aquella violencia dramatizada, tan evidentemente visible, y prestar más atención a la violencia sistemática y anónima que mantiene unida a esta sumatoria de individualidades atomizadas o comunidad infame que denominamos “sociedad” (•i•ek, 2010). Es decir, hablamos de aquella violencia que reviste carácter estructural, pues de ella pende la conservación del ordenamiento vigente, violencia para la cual la denuncia de sus hitos escandalosos no significa más que una concatenación de hitos visualizados, cadena absorbida por la amnesia que provoca la sucesión de escándalos mediatizados, estrategias de visibilización-enunciación, que parecen dar las bases para la continuidad a partir de su capacidad de recreación de lo que será definido como un problema, desde lo cual está implícitamente expuesta su propia (di)solución. Comenzaremos entonces con una breve revisión de la violencia objetiva que, en los términos anteriormente señalados, ha caracterizado la historia aún presente de El Salvador.

A finales del siglo XIX ingresan, con una hostil lógica desarrollista de la economía agroexportadora, una serie de reformas liberales, entre ellas la Ley de extinción de ejidos y tierras comunales indígenas, que fortalecen a las 14 familias que constituyeron la oligarquía cafetalera que, directa o indirectamente gobernó al país desde 1880 hasta 1979 (Velázquez, 2011:161). Esto constituyó paralelamente un proceso continuo de proletarización del campesinado -desde lo cual resulta bastante ilustrativa la existencia de cárceles al interior de las haciendas (Benítez, 1999)-, el empobrecimiento de los campesinos independientes, la legalización del despojo y el desplazamiento migratorio derivado de las modulaciones de la relación Estado-Capital. Evidentemente, este modelo poscolonial de dominación no se implementó de manera democrática, sino que requirió del constante apoyo de fuerzas militares y paramilitares (o Escuadrones de la muerte). La sucesión de golpes de Estado, dictaduras y juntas militares características del siglo XX, son prueba de ello. El tratamiento discursivo del campesinado 
rebelde como "bárbaro", al mismo tiempo incentivósu disciplinamiento a partir de la leva de soldados (Ching, 2011: 69), lo cual gestó una tradición militarista profundamente arraigada en las bases de la economía-política salvadoreña, que fue paulatinamente acentuándose en la segunda mitad del siglo XX debido a la posición geopolítica de El Salvador frente a los procesos de Cuba y Nicaragua por un lado, y a las políticas implementadas por la Alianza para el Progreso de J. F. Kennedy en 1961 por otro: utilización de fuerzas militares para servicios cívicos, creación de fuerzas paramilitares como la Organización Democrática Nacionalista (ORDEN) y el reclutamiento continuo de campesinos para el engrosamientos de las filas del ejército (Knut y Williams, 2011:77). La detonación de los antagonismos inherentes a este modelo de desarrollo, dada por las dos décadas de guerra civil, dejó aproximadamente 75.000 muertes y desapariciones civiles (Bourgois, 2005:15), además de gestar el éxodo que en la década de los ochenta llegó a albergarse a los suburbios de Los Ángeles, California.

La tradición militarista en El Salvador, marcó la historia del siglo XX de manera tan radical que fue uno de los ejes determinantes en los Acuerdos de Paz de Chapultepec en 1992, es decir, además del cese de fuego, uno de los temas fundamentales en los diálogos fue la desmilitarización del Estado y de las fuerzas políticas. Desde ahí se creó la Policía Nacional Civil que sustituyó a los antiguos cuerpos de seguridad pública, antaño subordinados a las Fuerzas Armadas (Policía Nacional, Policía de Hacienda y Guardia Nacional), que abrió paso a un discurso triunfalista de seguridad democrática que no obstante, no fue acompañado por reformas a las bases político-económicas sobre las cuales la violencia se cimentó. Al contrario, posteriormente a los Acuerdos de Paz, los regímenes gubernamentales llevaron consigo un fuerte proceso de neo liberalización: privatización de la banca, dolarización y firma del tratado de libre comercio, lo cual llevó a las antiguas familias de la oligarquía terrateniente tradicional a una nueva posición, esta vez desde el sector financiero y de servicios. No es casual entonces el proceso de remilitarización acontecido desde los albores del siglo XXI.

Como dice Naomi Klein, “el modelo económico de Friedman puede imponerse parcialmente en democracia, pero para llevar a cabo su verdadera visión necesita condiciones políticas autoritarias (...), algún tipo de trauma colectivo adicional que suspenda temporal o permanentemente las reglas del juego democrático” (2007:33). De hecho, en 1995, en una operación que suspende lo establecido en los Acuerdos de Paz y en la propia Constitución Política de El Salvador, se crean los Grupos de Tarea Conjunta, en donde la Policía Nacional Civil y el ejército, se acoplan para labores de seguridad pública o ciudadana en todo el territorio, además de la ampliación de facultades de policías y el aumento de su cantidad, cuestión gestada por una concatenación de reformas elaboradas entre 1998 y 2004, las cuales supusieron constituir un proceso de fortalecimiento institucional "necesario" para la administración del nuevo escenario de paz armada, autocalificado como democrático: entre ellas la creación del Ministerio de Gobernación (2001), secretaría que tiene la mayor concentración de poderes de la cual 
pende el manejo político de policías y cárceles. No está demás señalar, en este sentido, que el argumento de la necesidad objetiva, implica un juicio subjetivo relativo al objetivo que se quiere alcanzar y para el cual se utiliza dicho argumento, ya sea en el marco de la imposición de un orden o en la conservación del existente.

En este contexto llegan a El Salvador (además de a Guatemala y Honduras), las enormes cantidades de deportados provenientes del proceso de criminalización y estigmatización de otredades extranjeras que habitaban los guetos de Estados Unidos; desplazados re emplazados en los guetos centroamericanos y en sus extensiones penitenciarias. Los rostros tatuados con las marcas del emplazamiento en un territorio hostil, marcas del cobijo ya sea en la MS-13 o en la Mara 18, pasaron a ocupar el lugar que los antiguos regímenes armados daban al bárbaro rebelde, moreno, campesino, comunista... en una mezcla de alteridad y miedo que devela la continuidad poscolonial implícita en los regímenes de gubernamentalidad contemporáneos.

Quienes llegaban no eran solo los fantasmas de las remesas, sino cuerpos jóvenes portadores de una triple forma de exclusión que había devenido inclusión irreversible en un espacio otro, sin patria: no eran simplemente víctimas; eso se veía en sus rostros y gestos. Morfología constituida en una negociación temporal y espacial específica con la violencia: no un cuerpo que existe en su entorno, pues no existe como cuerpo sin entorno y por ende éste no le es exterior (Butler, 2010). Residuos ingobernables de la violencia: ni víctimas ni súbditos, entonces... enemigos. La importación de las políticas de Tolerancia Cero, traducidas como políticas de Mano Dura y de Ultra Mano Dura, hizo lo que restaba en esta morfología. Los regímenes gubernamentales que proclamaron la mediación y el consenso a través del simulacro político del voto y la publicidad, gestionaron estos paradójicos acontecimientos de la continuidad abriendo paso a aquella “novedad” glorificada como globalización y redefiniendo, como fundamento de la política formal, la construcción mercadotécnica del miedo como dispositivo coercitivo de control y cohesión social a partir de la identificación, selección, manejo y uso de las categorías de peligro y seguridad. En otras palabras, estableciendo la partición policial de quien será aceptado como ciudadano y quien será su oposición constitutiva, desde una concepción de la libertad invocada como base racional e instrumental para la ejecución de prácticas coactivas. No casualmente podemos citar al Leviatán hobbesiano como introducción para comprender la legitimación de las operaciones extra-jurídicas que revisaremos en el próximo apartado: "En casos de hostilidad declarada toda la inflicción de un mal es legal. De lo cual se sigue que si un súbdito, de hecho o de palabra, con consentimiento o deliberadamente, niega la autoridad del representante del Estado (...) puede legalmente hacérsele cualquier daño que el representante quiera, ya que al rechazar la condición de súbdito, rechaza la pena que ha sido establecida por la ley, y, por consiguiente, padece ese daño como enemigo del Estado” (Hobbes, 1998: 257). Revisaremos más en profundidad este tema en el siguiente apartado a partir del análisis de la promulgación de la Ley Anti 
Maras de 2003, la Ley de Asociación ilícita de 2004, la Ley para el combate de las actividades delincuenciales de las asociaciones ilícitas especiales del mismo año y la Ley de proscripción de maras de 2010, que radicaliza aún más la penalización de la pertenencia a estos grupos, más allá de cualquier hecho calificado como delito o, en otras palabras, haciendo de la pertenencia el hecho que es delito.

\section{De grupo de amigos a agrupación ilícita}

El argumento de la necesidad es el que por una parte no reconoce ley, y por la otra, crea y produce su propia arma gubernamental: la ley. A partir del Decreto legislativo 653 del 6 de diciembre de 2001 que introduce reformas en las facultades de la Policía Nacional Civil, modulaciones en su estatuto orgánico, se abre la puerta para la gestión del discurso securitario que articuló una estrategia de populismo punitivo, en donde la figura de la víctima -definida por los ejes de problematización de su propio programa político- y el desplazamiento del daño desde la imagen de una víctima específica hacia la abstracción del Estado y La Sociedad pasó a ser el recurso simbólico de legitimación del delineamiento de la denominada seguridad democrática.

Aquí, debido al énfasis y relevancia asignada a la metáfora de la guerra contra la delincuencia, se produce una torsión sobre algunos ejes que, desde la implementación de la Constitución Política, parecían ser la guía de la definición del término democracia y Estado de Derecho. El importante acento en los derechos y garantías fundamentales que se encontraba inscrito -al menos- en las primeras etapas de la Constitución, fue así disolviéndose de manera paulatina a partir de los decretos emitidos y aprobados para el "eficaz" funcionamiento del sistema punitivo delimitado por este campo discursivo.

En este contexto, era, sin embargo, "necesario” un comodín judicial que eludiese la demarcación del dispositivo de la culpa en términos individuales, ya que el discurso en cuestión apelaba a clases adversarias más que a hechos individualmente punibles. Ahí nace la Ley Anti Maras emitida por Decreto Legislativo 158, del 9 de octubre de 2003, con todas sus sucesivas reformas posteriormente derogadas por el Artículo 36 del Decreto legislativo 305 o Ley para el combate de las actividades delincuenciales de grupos o asociaciones ilícitas especiales. Lo que ocurrió en ese entonces, fue que la claridad expuesta en el título de la ley, generó tanta controversia que la MS-13 o Mara Salvatrucha, paralizó San Salvador exigiendo su derogación: objetivo parcialmente logrado ya que a pesar de su derogación el vocabulario legislativo reintrodujo en esencia a la misma ley a partir de nuevos decretos emitidos el siguiente año. Es ahí donde ingresa la categoría de asociación ilícita. Como dice el Artículo 345 del decreto 393, del 30 de julio de 2004: "Serán consideradas ilícitas las agrupaciones, asociaciones u organizaciones temporales o permanentes, de dos o más personas que posean algún grado de organización, cuyo objetivo o uno de ellos sea la 
comisión de delitos, así como aquellas que realicen actos o utilicen medios violentos para el ingreso de sus miembros, permanencia o salida de los mismos”.

Como es posible observar, el delito propiamente tal se contempla en esta nueva categoría penal como eventual “objetivo”-cuestión que evidentemente no consta de pruebas de la comisión del hecho clasificado como tal-y aun así, éste queda relegado a un segundo lugar, incorporándose la clasificación del ritual de ingreso, permanencia o salida del grupo, lo cual está pensado en función de las maras, aun cuando en este segundo decreto no aparece explicitado el término como enunciado. Por esta razón, en septiembre del mismo año se elaboró un tercer decreto legislativo, esta vez, mucho menos ambiguo, dirigido a una clase especial de asociación ilícita, aplicable a toda persona mayor de doce años, con el objetivo de “establecer un régimen especial para el combate de las actividades delincuenciales de los grupos o asociaciones ilícitas especiales conocidos como maras o pandillas” (Art. 1, Decreto legislativo 305).

Estas “asociaciones ilícitas especiales” serán “aquellas agrupaciones de personas que en su accionar afecten la pacífica convivencia social, el orden público, el decoro, las buenas costumbres o la seguridad ciudadana” (Art. 3). “Así mismo, se considerarán elementos adicionales para definir la existencia de un grupo de personas que conforman una Mara o Pandilla, cuando se cumplan dos o más de los siguientes requisitos: a. Que se agrupen o reúnan habitualmente. b. Que señalen injustificadamente segmentos de territorio como exclusivo en relación con otras Maras o Pandillas. c. Que tengan señas o símbolos como medio de identificación o reconocimiento con la Mara o Pandilla. d. Que se marquen el cuerpo con tatuajes o cicatrices, como medio de identificación o pertenencia a la misma” (Art. 3).

Es decir, nos encontramos frente a un dispositivo semejante al que Michel Foucault calificó como racismo de Estado (Foucault, 2000), esta vez, sin embargo, no derivado de teorías de raza sino de cultura o, más específicamente, de “contra cultura”. De tal manera que no es la retirada de la ley o la ausencia de esta, lo que produce precariedad, sino los efectos mismos de la ilegítima coacción legal o el ejercicio del poder estatal liberado de los condicionamientos de toda ley (Butler, 2010: 52): tratamiento racista en sentido hiperbólico, pues no asume su inferioridad racial -en términos explícitos- sino su exclusión a priori delo humano. De manera que ciertas normas exclusivistas y persecutorias se convierten, a la vez, en precondición y teleología de la cultura, violencia practicada en nombre de la conservación de cierta modernidad que constituye la amenaza más concreta a la libertad, instalada como origen y fin de lo culturalmente pensable.

Todas estas indicaciones utilizadas para la identificación del enemigo, además de incluir la pertenencia dentro de la gama de elementos punibles (prisión de tres a seis años sin haberse probado la comisión de un hecho inscrito en el código penal común, Art. 4) modifican el estatus del proceso penal cuando el imputado esté dentro de esta clasificación, lo cual suspen- 
de todas las garantías procesales y procesal-penales del imputado. Entre ellas, cualquier hecho clasificado como falta, si es cometido por un/a marero/a pasa a ser penado con condenas que varían entre los dos y seis años de cárcel (Arts. 5-11) sin posibilidad de reparación de daños ni de penas alternativas ni de beneficios de pre-liberación ya que la pertenencia a una mara pasa a estar inscrita dentro de la categoría de crimen organizado, con todas las excepciones que esto implica (Arts. 13-22), incluyendo la posibilidad de que un parte policial sea usado como prueba acusatoria, además de la existencia de testigos criteriados o anónimos (Art.29).

Por último, en 2010, tras la caída de la Alianza Republicana Nacionalista (ARENA) y el ingreso del Frente Farabundo Martí para la Liberación Nacional (FMLN) al poder ejecutivo, antaño organismo de coordinación de las cinco agrupaciones guerrilleras que lucharon contra el gobierno militar en la guerra civil, paradojalmente, posiblemente como estrategia publicitaria, se crea una nueva ley que complementa y acentúa aún más los elementos de los decretos anteriormente revisados: la "Ley de proscripción de maras, pandillas, asociaciones y organizaciones de naturaleza criminal” en vigor desde septiembre de 2010, esta vez explicitando la prohibición de la existencia de las maras (Art. 1), eliminando cualquier derecho ciudadano de sus participantes (Art. 3) y abriendo paso a la confiscación de cualquier bien mueble o inmueble, cuentas bancarias, etcétera, que pasan a ser parte de los bienes del Estado (Arts. 5-7). Es decir, sumando al encarcelamiento masivo de los/as jóvenes mareros/as, su desnudez política y económica, y por cierto, la de todos/as quienes penden de ellos/as. Es importante en este sentido, destacar que las fuerzas políticas que antaño se enfrentaron en la guerra civil, tras los Acuerdos de Paz, han sido, ambos de manera consensuada e independientemente de su supuesto antagonismo político (desde la dicotomía Derecha-Izquierda) cómplices de este proceso de criminalización y reproducción de las estructuras fundamentales de la violencia.

Toda esta secuencia de decretos con fuerza de ley han generado un aumento explosivo en la cantidad de población reclusa (vigilada conjuntamente por policías y personal del ejército), teniendo hoy (2015) El Salvador 31.433 presos dentro de un total de 6.143 millones de habitantes, esto es, una tasa de 489 presos por cada 100 mil habitantes (siendo el promedio latinoamericano 236) ${ }^{2}$, a lo cual hay que sumarle los más de 3 mil presos hacinados en las bartolinas dependientes de la Policía Nacional Civil y los presos menores de edad secuestrados en las jaulas que el eufemismo institucional denomina "Centros para el Desarrollo de la Niñez y la Adolescencia”.

Un dato interesante es que El Salvador cuenta con una de las cantidades menores en el contexto latinoamericano de presos en prisión preventiva, es decir, presos no condenados (26\%, siendo el promedio latinoamericano 45.1\%), lo cual dista mucho de tener algún vínculo con la capacidad investigativa de los casos imputados, sino con que la sospecha está inscrita en las categorías penales antes revisadas y por tanto, como hemos visto, 
más allá del hecho individual que es delito, el delito se encuentra subsumido en esta tecnología clasificatoria que, teniendo amplias cualidades extra jurídicas, está, de hecho, inscrita en la ley. De ahí la vigencia y pertinencia de la observación de Walter Benjamin: "Los intereses del Derecho por monopolizar la violencia respecto de la persona aislada no tienen como explicación salvaguardar fines jurídicos, sino salvaguardar al Derecho mismo" (Benjamin, 1995: 162), lo cual podemos entrelazar con la observación de Giorgio Agamben respecto al problema del monopolio del Derecho, la violencia y el lugar estratégico del proceso y la celebración del juicio con independencia de su carácter o contenido específico: "El derecho no tiende en última instancia al establecimiento de la justicia. Tampoco al de la verdad. Tiende exclusivamente a la celebración del juicio, con independencia de la verdad o de la justicia” (Agamben, 2000:9).En otras palabras, hablamos de un sistema jurídico (en dónde debemos incluir claro está, el sistema penal en la rama del derecho penal), basado en una lógica dual que por un lado se fundaría nominalmente en una estructura normativa y jurídica en sentido estricto (potestas) y otro anómico o meta-jurídico (autoritas), ambos procesos de mutua dependencia (Agamben, 2007: 124-127). De ahí deriva que el aspecto normativo del Derecho pueda ser impunemente cancelado o contrariado por la violencia gubernamental, sin que esto signifique una necesaria disfunción de ambas lógicas sino su funcionamiento complementario más eficaz, lo cual sin embargo, evidencia la falacia liberal que plantea al estado de excepción como paréntesis temporal o estado de emergencia espacial y temporalmente acotado.

Por esto la relevancia de la noción de campo de concentración, lugar de materialización del estado de excepción y de la consiguiente creación de un espacio para la "vida desnuda" (Agamben, 1889:54): centro de detención, confinamiento e incluso genocidio, en el que se encierran personas a partir de una lógica clasificatoria por su pertenencia a un grupo genérico en lugar de sus actos individuales, sin garantías judiciales (ni individuales ni colectivas), aunque puede existir un cobijo legal que lo respalde. La diferencia con una cárcel, en este sentido, supone ser la presencia de garantías judiciales a que tienen derecho los sujetos-presos a esta última, y a su vez, la ubicación del dispositivo de la culpa, que en el caso de los regímenes penitenciarios se encontraría en el individuo aislado, en el hecho que es delito, y no en su pertenencia colectiva, argumento desde el cual, hipotéticamente se desprende su potencial disciplinario u ortopédico en el que aquel cuerpo individual es reformado y eventualmente, después del cumplimiento de su condena, su deuda, es reintegrado a la sociedad normada. Esta distinción entre estas dos formas de confinamiento precisa ser puesta en interrogación, al igual como aquel umbral de indiferenciación entre el Estado de Derecho y el estado de excepción.

\section{La guerra, el miedo y sus usos}

En este contexto, la noción de guerra, por un lado diluida y por otro usada como eslogan político publicitario, asume importantes mutaciones: 
cambios en sus marcos interpretativos y en sus espacios y formas de ejecución. Siguiendo el vínculo que establece Karl von Clausewitz (2010) entre guerra y política, aquí la guerra se muestra -desde la noción de espectáculo propuesta por Guy Debord (2007), como una de las facetas primordiales de la política global en un sistema absolutamente complementario a los regímenes de gubernamentalidad armada autodenominados como pacíficos y democráticos. Desde el supuesto fin de la Guerra Fría (con sus respectivos correlatos latinoamericanos), la violencia militar y la imposición de formas político-económicas sustentadas por la fuerza de las armas se han convertido en un recurso continuo, normal y cotidiano. La guerra, en sus mutaciones, se presenta como herramienta fundacional del Estado, en tanto fundamento continua y poliformemente reactualizado para la vigencia del mismo, en un contexto en donde la metáfora de la guerra pasa a asumir un carácter fáctico específico, pero desde el cual lo "metafórico" del enunciado se enmarca en la disolución de los límites de su acepción convencional o literal. Metáfora que produce un desorden, pero que por ser tal, del propio desorden emerge otro orden discursivo al simbolizar una situación por medio de otra, infundiendo en el corazón de la situación simbolizada las huellas vinculadas a la situación que ella simboliza, y por tanto crea, produce realidad. Desde ahí la relevancia de la inversión del aforismo de Clausewitz planteada por Foucault: no la guerra como continuación de la política por otros medios, sino la política formal como continuación de la guerra (Foucault, 2000), desde lo cual la paz no es, en ninguna instancia, la eliminación de la guerra sino el ejercicio del poder como guerra continua en su acepción más neutralizante.

En los términos de • • • ek, la hipocresía de esta tecnología consiste en que quienes suponen combatir la "violencia subjetiva”, hacen uso de una violencia sistémica, que no casualmente genera y reproduce los propios fenómenos que supone aborrece $(\bullet i \bullet e k, 2010$ : 243). Desde ahí el autor se pregunta: “¿Qué es el robo de un banco comparado con la fundación de un banco? En otras palabras ¿qué es el robo que vulnera la ley comparado con el robo que tiene lugar dentro de los límites de la ley?” (Ibíd:143). O, si extendemos la interrogante, ¿qué es el crimen organizado frente a un poder estatal que hace la guerra organizada contra dicha categoría? En este sentido, es importante destacar que el "problema” de las maras no es necesariamente el robo, ni el tráfico de armas, ni la distribución de drogas, ni el tráfico de personas que, en busca de trabajo, cruzan clandestinamente las fronteras que van desde Centroamérica a Norteamérica, sino que esto lo hacen fuera de los límites de la ley, sin reconocer la autoridad de ningún Estado, ni de sus constructos culturales normados, en una forma de organización contra estatal y contra cultural explícita.

Como hemos dicho anteriormente, la violencia no es propiedad exclusiva de nadie y condenarla como intrínsecamente "mala" no es más que una operación ideológica, una mistificación que colabora con la invisibilización de las formas fundamentales de la violencia estructural, obscureciendo los cimientos desde dónde lo visibilizado como violencia nace. En este sentido, estos usos, no sólo implican la neutralización política 
derivada de la (re) producción de las categorías de peligro y seguridad, con la respectiva exposición de la imagen del Estado-Capital como mediación existencialmente neutra, que supone preservar con la violencia institucional a un supuesto "tejido social" que la misma relación destruye, sino que además, la ubicación de la causa última de la violencia en el miedo al prójimo, constituye la puerta de ingreso para el aprovechamiento político-económico de lo que ha sido definido como problema: económico pues la rentabilidad del discurso securitario en servicios de vigilancia, concesiones carcelarias, guardias armados, cámaras, alarmas, etcétera es abrumadora; político pues la heterogeneidad del problema ingresa en la reducción publicitaria propia de las medidas represivas y, a su vez, reproductoras del carácter profundamente hostil de la administración policial.

En este contexto, los medios de producción-difusión masiva de enunciados, configuran el escenario adecuado para la justificación de la forma, densidad y direccionalidad en que se extiende la violencia, como a su vez cuáles de sus formas serán calificadas como legítimas y cuáles no. Es por tanto, la contraparte de la violencia estatal directa que, como ella, se organiza en grandes corporaciones de vocación monopólica que forman parte de una extensa red corporativa que sobrepasa los límites fronterizos de cualquier Estado.

En este sentido, la codificación de posibles demandas del campo político asume un carácter policial administrativo "nuevo"(en su reactualización), al ser éstas sintetizadas en el marco interpretativo del discurso securitario contemporáneo que, a partir de la selección programática de ciertos tipos de ilegalismos, su visualización exacerbada, dirime también respecto a los espacios de invisibilización sobre los cuales el mismo discurso se sostiene. Combinación de paroxismo e hipertrofia tanto de los massmedia como del Derecho y lo militar-policial en donde se mezclan las ideas de delincuente a castigar y enemigo a exterminar, pero a su vez, de delincuente y enemigo a (re)producir, constituyéndose un escenario de guerra lo suficientemente difuso como para alcanzar en potencia a cualquier contingencia.

Este enfoque binario no obstante, no es más que la forma en que se (re)articula una nueva faceta de la percepción unitaria, o en otros términos totalitaria, de la conformación universalista y colonial de los estados modernos de esta extensión subordinada de occidente, ya que tiende primero, a unificar todas las diferencias en ese otro genérico y avieso, para luego confeccionar la unidad espectacular de los entes cohesionados y normados en esta doble dimensión de los procesos hegemónicos que incorpora la fuerza y el reconocimiento, dispositivos que para alcanzar esa unificación espectacular recurren constantemente a la violencia simbólica y represiva; a la guerra en su versión más insípida desde una narración neutralizante de la paz que se funda en coerción revestida de "anuencia ciudadana”.

La visualización sensacionalista de la imagen de la víctima, la selección de quien será la víctima en esta hostil vorágine (y quien no será inscrita 
en esa categoría), y a su vez, el desplazamiento del daño desde la imagen de una víctima específica hacia la abstracción del Estado y La Sociedad (o el eventual peligro que un cuerpo contiene respecto a estas formaciones metafísicas), posiciona al argumento de la necesidad securitaria en tanto necesidad de todos. El elemento ficcional propio de la operación ideológica que aquí está en juego, obedece a una paradoja, ya que, si bien como dice •i•ek, "la sociedad" no existe, pues está atravesada por una escisión antagónica que no se puede integrar al orden simbólico establecido, la apuesta de la fantasía ideológica es construir una imagen de La Sociedad que sí exista (una sociedad en la que la relación entre sus partes sea orgánica), imagen para lo cual el orden simbólico que lo sostiene exige la recreación de un antagonismo vaciado de contenido político o, en otros términos, traducido por una semántica policial (•i•ek, 1992: 173).Cuando hablamos de populismo punitivo entonces, no podemos referirnos exclusivamente a las prácticas implementadas por los discursos securitarios a los cuales hemos hecho referencia, sino más bien al dispositivo que efectivamente hace posible y aceptable la comisión de estos hechos, ya que en términos de la denominada Opinión Pública son calificados como necesarios, lo cual más que ser en estricto rigor algo falso, constituye un imperativo de verdad. Hemos de entender entonces que para hablar de populismo punitivo el discurso al que hemos hecho mención “nos” requiere. Requiere en términos gramaticales, tanto a la primera como a la tercera persona plural, en una torsión comunicativa que elimina a la segunda. Esto es, el que no solamente implica una dilución de las fronteras entre lo policial y lo marcial, sino que por sobre todo la incorporación de estos imperativos de verdad en las formas de ver y entender el mundo, al menos en las de las capas que participan del sistema de sufragio, es decir, una dilución entre lo civil y lo netamente policialmarcial. El miedo ingresa entonces como tecnología de desarticulación de la noción de comunidad que introduce la sospecha frente al prójimo y la cámara viviente en cada retina, confeccionándose a su vez una rearticulación policial del Uno que no es comunal sino espectacular. Populismo punitivo como último enclave de la noción de representación que, como tal, constituye el cimiento ficcional de los regímenes de dominio autodenominados democráticos. Distancia abismal que por definición existe entre representantes y representados: representación ilusoria como acto en nombre de una entidad constituida retroactivamente por el mismo nombre. Representación de lo ya antes presentado como propaganda electoral. Delimitación espectacular de víctimas y victimarios condenada a la insatisfacción endémica proveniente de este espacio en el tiempo, esta temporalidad política. 
Polis, Revista Latinoamericana, Volumen 14, $N^{\circ}$ 42, 2015

\section{Notas}

${ }^{1}$ Doctora en Estudios Latinoamericanos, Universidad Nacional Autónoma de México. Ha trabajado sobre temas contiguos en investigaciones para el Consejo Latinoamericano de Ciencias Sociales (CLACSO).

${ }^{2}$ Según un promedio (de elaboración propia), a partir de los datos de los diferentes organismos encargados en cada país entregados entre los años 2014 y 2015. Si es de interés de el/la lector/a, los datos específicos de cada país, incluyendo El Salvador, pueden encontrarse en el siguiente link: http://www.prisonstudies.org/world-prisonbrief. 


\section{Bibliografía}

Agamben, Giorgio (2007), Estado de excepción. Adriana Hidalgo, Buenos Aires.

Ìdem (1998), ¿Qué es un campo? Artefactos. Pensamiento sobre la técnica, Buenos Aires.

Benítez, Alma (1999), ¿Sistema penitenciario en Centroamérica o bodegas humanas? CODEHUCA, San José, Costa Rica.

Benjamin, Walter (1995), Para una crítica de la violencia. Leviatán, Buenos Aires.

Bourgois, Philippe.(2005), “Más allá de una pornografía de la violencia. Lecciones desde el Salvador” en Ferrándiz, Francisco yFeixa, Carlos (eds.) Jóvenes sin tregua. Culturas y políticas de la violencia. Anthropos, Barcelona.

Butler, Judith (2010), Marcos de guerra. Las vidas lloradas. Paidós, Buenos Aires.

Ching, Erick (2011), El Salvador: Historia Mínima. 1811-2011. Universidad de El Salvador, San Salvador.

Clausewitz, Karl (2010), De la guerra. Colofón, Distrito Federal.

Debord, Guy (2007), La sociedad del espectáculo. Pre-textos, Valencia.

Foucault, Michel (2000), Defender la sociedad. Fondo de cultura económica, Buenos Aires.

Hobbes, Thomas (1998), Leviatán o la materia, forma y poder de una república eclesiástica y civil, Fondo de cultura económica, Distrito Federal.

Klein, Naomi (2007), La doctrina del shock: el auge del capitalismo del desastre.Paidós, Barcelona.

Knut, Walter y Philip, Williams (2011), El papel político del Ejército salvadoreño (1930-1979) Universidad de El Salvador, San Salvador.

Tiqqun (2009), Llamamiento y otros fogonazos. Ediciones Acuarela y Machado, Madrid.

Velásquez, Carlos (2011), “La Consolidación Oligárquica Neoliberal en El Salvador y los Retos para el Gobierno del FMLN”, en Revista América Latina, Universidad ARCIS, Núm. 10, Santiago. 
Polis, Revista Latinoamericana, Volumen 14, $N^{\circ}$ 42, 2015

•i•ek, Slavoj (2009), Sobre la violencia. Seis reflexiones marginales. Paidós, Barcelona.

Ídem (1992), El sublime objeto de la ideología. Siglo XXI, Distrito Federal.

Recibido: 12.11.2015

Aceptado: 20.12.2015 